\title{
Potential Importance of Sociological Tourism for Madagascar's Protected Areas and Those Who Live Around Them
}

\author{
Chris Birkinshaw
}

Tourism is a ubiquitous part of the management plans of Madagascar's accessible protected areas (and even some that are inaccessible) where it is seen as an economic justification for conservation and as a means to finance conservation activities and provide benefits for the communities surrounding the nature reserves. This tourism is normally focused on flora and fauna and little attempt is made to interest the tourist in the lives of local people. Here, consideration is given to why this is so and the possible benefits of developing sociological tourism around Madagascar's reserves.

Madagascar has a rich, strange, unique and appealing flora and fauna and it is to be expected that the written and oral interpretive services associated with reserves should focus on these, particularly because biodiversity is the perceived raison d'être for these sites. However, there is no reason why this emphasis should exclude information also being provided on the lives of the local people who interact with conserved ecosystems. On the rare occasions when such information is made available it is superficial, inaccurate and negative, with the indigenous people presented either as one of the problems to conserving the biodiversity or stereotyped as people clinging to rigid or bizarre traditions.

It seems unlikely that tourists are not interested in the lives of those who live around protected areas: indeed, most people are naturally more interested in their own species than other species. Casual observations at protected areas suggest that some tourists are deeply interested in the local residents. However, this interest is masked by guilt and embarrassment concerning the differences in their respective wealth, a reticence to probe into the lives of others, and a fear about getting involved with often desperately poor people; all compounded by an inability to communicate in the vernacular. Occasionally this interest emerges and then their guides must struggle to keep their interest "properly" focused on the wildlife. Thus, a more likely explanation for the lack of capacity for sociological tourism at Madagascar's reserves is the narrow perspective of their managers who believe that their protected area solely concerns the conservation of "pristine" ecosystems of which people play no part (see Harper 2002). On the contrary, rather than being considered part of the wealth of the area, the residents are seen as one of its problems. It is also possible that the managers may be embarrassed by the negative effects of reserves on the lives of some individuals in the local population. Given this background, it is not surprising that reserve managers make little attempt to provide the visiting tourists with access to information concerning the real lives of local people: yet, if they did, their project might be improved.

Good sociological tourism must never treat the local people as an exhibit. The ideal scenario would be one in which the residents held most of the power for the management of their interactions with tourists, although clearly these interactions would need to be facilitated by a sensitive translator. Often, part of the development strategy around Malagasy reserves is the creation of a range

\section{Correspondence}

Chris Birkinshaw, Missouri Botanical Garden, BP3391, Antananarivo 101, MADAGASCAR.

chris.birkinshaw@mobot-mg.org

Ethnobotany Research \& Applications 3:383-384 (2005) 
of associations that provide the context for material and training support. Such associations might include those for beekeepers, fishermen, rice growers, women and babies, vegetable growers, and many more. These groupings could also provide the ideal context for the proposed sociological tourism. A tourist interested in, say, bee keeping would be led by the translator to meet one or more of the members of the beekeepers association where he or she would facilitate a free interchange between the tourist and the beekeeper(s). At its best, the exchange of information would flow in two directions and the interaction would be a true dialogue. The encounter would take place under rules developed by the association and the beekeeper and the translator would be paid a standard fee. The reserve infrastructure should be involved in the endeavor only to the extent of directing interested tourists from the reserve reception to the independent translator.

If equitable interchange between tourists and local people can be engineered, there would be several worthwhile benefits. The tourist would gain real knowledge of the complex and diverse lives of rural Malagasy as opposed to the stereotypes of historically-frozen traditionalists or ignorant destroyers to which they have likely been hitherto exposed. Hopefully too they will gain much pleasure from interacting with someone normally inaccessible because of linguistic and sociological barriers. Although more westerners are now traveling to developing countries such contact is rare and should be encouraged as a means of improving understanding and removing prejudice concerning the lives of people in these countries. The local person would gain financially and perhaps also take pleasure from the interest shown in their work or lives and from their increased knowledge of the lives of others. Many studies have shown that the benefits of nature reserves are distributed very unequally among the members of local communities (e.g. Harper 2002). Often it is those who are young, healthy, educated and living close to reserve reception points that obtain most. Sociological tourism, offers the possibility of distributing the benefits somewhat more widely but clearly, once again, it is those who are confident and live close to tourist haunts who are likely to benefit the most.

An important secondary effect of sociological tourism may be to encourage the reserve managers to see the local people as a potential asset rather than as simply a problem. The tourist too may act as a powerful advocate for local people and provide them with new lines of communication with reserve managers. Finally, sociological tourism might also act to increase the importance of sociology in conservation management that is currently overwhelmingly dominated by the biological perspective. Currently, although sociological studies are often included as part of the research used to develop the management plans of Malagasy protected areas, these are normally superficial and lead to bad management decisions (Hanson 1997).
In conclusion, sociological tourism clearly will not resolve all the problems associated with the management of protected areas in Madagascar but it may make a contribution to improving this management by: a) promoting a real and satisfying exchange of understanding between the tourist and the resident; b) benefiting some residents financially who might otherwise lose from the establishment of the reserve; c) encouraging reserve managers to see those living in or around reserves as historically or currently part of the ecosystems that they aim to conserve with consequent benefits for the local communities and the conservation of biodiversity. I recommend that a pilot study be launched to evaluate whether a viable and nonexploitative sociological tourism can be developed adjacent to Madagascar's protected areas that yields worthwhile benefits for all concerned.

\section{Literature Cited}

Hanson, P. 1997. The politics of need interpretation in Madagascar's Ranomfanana National Park. Ph.D. Dissertation, Department of Folklore and Folklife, University of Pennsylvania.

Harper, J. 2002. Endangered Species: Health illness and death among Madagascar's people of the forest. Carolina Academic Press, Durham, North Carolina. 